\title{
Comportamento de animais silvestres em cativeiro: protocolos para ariranha (Pteronura brasiliensis) e chimpanzés (Pan troglodytes) *
}

Daniel Louzada-Silva ${ }^{1}$

\begin{abstract}
RESUMO - Dois protocolos de observação comportamental de mamíferos silvestres foram elaborados no Jardim Zoológico de Brasília, um para ariranha (Pteronura brasiliensis) e o outro para chimpanzés (Pan troglodytes). O de ariranhas foi usado para acompanhar o comportamento reprodutivo, cuidados parentais e o desenvolvimento dos filhotes. O de chimpanzés serviu para o acompanhar indivíduos recém-chegados ao Zoológico de Brasília e de sua adaptação. Os dois protocolos vêm sendo utilizados por alunos de graduação em Biologia e Psicologia em aulas de campo.
\end{abstract}

Palavras-chave: comportamento, reprodução, cuidados parentais, ariranha, Pteronura, chimpanzé, pan, Jardim Zoológico de Brasília.

\section{Wild animals in captivity behavior: protocols for giant otter (Pteronura brasiliensis) and chimpanzees (Pan troglodytes)}

\begin{abstract}
Two protocols for behavioral observation of wild mammals in captivity were developed at Brasília Zoo, one for giant otter (Pteronura brasiliensis) and the other for chimpanzees (Pan troglodytes). The giant otter protocol was used on observations of reproductive behavior and offspring development. Chimpanzee's protocol was used to evaluate the adaptation of new individuals at Brasília Zoo. Both the protocols have been used by Biology and Psychology for field classes.
\end{abstract}

Key words: behavior, reproduction, parental care, giant otter, Pteronura, chimpanzee, Pan, Brasília Zoo.

\footnotetext{
*Este e os dois artigos seguintes compõem uma sequência de estudos e considera-se a leitura destes na ordem que aqui são apresentados. (N.E.)

${ }^{1}$ Professor de Fisiolgia Humana no UniCEUB. SEPN 707/907, campus do UniCEUB, bloco

9, Faculdade de Ciências da Saúde. CEP 70.790-075, Brasília, DF.daniel.louzada@uniceub.br
} 
O estudo do comportamento de animais silvestres é fundamental para programas de criação e reprodução em cativeiro, que é entendida como resultado de condições físicas e mentais saudáveis dos animais e é um objetivo a ser alcançado por zoológicos e criadouros científicos. A falta de informações sobre o comportamento de uma espécie em seu ambiente natural limita nossa capacidade de atender às suas necessidades em cativeiro. Por outro lado, grande parte do que se conhece sobre o comportamento de algumas espécies, como é o caso da Pteronura brasiliensis, é resultado de estudos em cativeiro. (SALVO SOUZA \& BEST, 1982; LOUZADA-SILVA \& SARTORI, 1998; GARCIA et al., 2001; YNTERIAN, 2004)

Conhecer o comportamento de uma espécie em cativeiro é, portanto, condição básica para o sucesso no seu manejo e bem estar. Os estudos comportamentais incluem a determinação de um repertório, a definição de metodologia de coleta e tratamento dos dados e têm como objetivo final o desenvolvimento de parâmetros de comparação que permitam definir novas prioridades e redirecionar esforços. (ESTES, 1991; BOEHN, 1996; GARCIA et al., 2001; WHITEN \& BOESCH, 2001)

Entre 1995 e 1998, dois protocolos experimentais foram desenvolvidos no Jardim Zoológico de Brasília (JZB), da Fundação Pólo Ecológico de Brasília, para o estudo do comportamento de ariranhas e chimpanzés. Todos os envolvidos na elaboração e/ou revisão desses protocolos eram, à época, alunos de graduação do curso de Biologia do Centro Universitário de Brasília (UniCEUB) e trabalharam sob minha orientação. Esses protocolos são amplamente utilizados nas disciplinas de graduação Laboratório de Fisiologia Humana I (curso de Psicologia), Comportamento Animal e Estágio Supervisionado (curso de Biologia) para observações de campo e como referência para a montagem de outros protocolos.

\section{Pteronura brasiliensis}

O protocolo comportamental de ariranha foi desenvolvido com base em observação de animais em cativeiro no JZB. (Pteronura brasiliensis, CARNIVORA MUSTELIDAE, ZIMMERMANN, 1780) Descreve os comportamentos observados, orienta sobre como coletar de dados e traz uma planilha para sua compilação. Entre abril de 1995 e dezembro de 1998, três de nós, Louzada-Silva, Sartori e Marques, desenvolvemos este repertório e testamos a metodologia de coleta de dados baseada na observação de dois casais de ariranhas e seus filhotes no JZB. A partir de 1999, grupos variados de alunos de graduação em Biologia do UniCEUB utilizaram este repertório em disciplinas, como Comportamento Animal, o que nos permitiu seu aprimoramento. Em 2002 e 2003, Louzada-Silva e Godoy desenvolveram a planilha que se encontra em anexo. 
Pteronura brasiliensis é uma espécie endêmica da América do Sul, o maior mustelídeo vivo e um dos maiores mamíferos neotropicais. Existe, no Brasil, outra espécie de lontra, Lontra longicaudis, que é menor, solitária e tem hábitos crepusculares. A ariranha é diurna, vive em grandes grupos sociais, em rios e lagos. Chega a medir mais de $1,8 \mathrm{~m}$ e pesar $33 \mathrm{~kg}$. Sua distribuição original estendia-se desde a Argentina até a Colômbia. Atualmente, exceto no Suriname onde ainda é abundante, é considerada praticamente extinta na Argentina e no Uruguai, seriamente ameaçada no Equador, Colômbia e Peru. Foi descrita como a espécie mais ameaçada da Venezuela em 1978, e não há informações sobre o "status" desta espécie na Bolívia, no Paraguai e na Guiana. (DUPLAIX, 1980; THORNBACK \& JENKINGS, 1982; FONSECA et al., 1994; CARTER \& ROSAS, 1997; EMMONS \& FEER, 1997; BRASIL, 2003)

A ariranha é classificada pela IUCN como ameaçada (EN A1acde) e está incluída no Anexo I da CITES e na Lista das Espécies da Fauna Brasileira Ameaçada de Extinção. (IUCN, 2003; CITES, 2003; IBAMA. 2001; BRASIL, 2003) A espécie era comum em todos os rios brasileiros, exceto nos do nordeste. Hoje, está reduzida a pequenas populações, principalmente no Pantanal e na Amazônia. (FONSECA et al., 1994; SALVO SOUZA \& BEST, 1982; CARTER \& ROSAS, 1997) A caça para a obtenção de peles foi forte fator de pressão sobre as populações no Brasil até a década de 70. Apenas entre 1960 e 1967, foram exportadas 40.663 peles de ariranhas. (SALVOSOUZA \& BEST, 1982)

A destruição de habitat, principalmente no Sul e Sudeste, a poluição de rios e lagoas por mercúrio e agrotóxicos e a construção de hidroelétricas são outros fatores que contribuíram para a extinção, a redução e o isolamento de populações no Brasil. (FONSECA et al., 1994; CARTER \& ROSAS, 1997) Apesar de não haver registro de ariranhas no Nordeste brasileiro, na literatura recente, a espécie pode ter ocorrido em Alagoas, Sergipe, Bahia e Pernambuco, ao longo do Rio São Francisco. (CABRERA, 1957)

\section{Pan troglodytes}

Pan troglodytes é classificada pela IUCN como espécie ameaçada (EN A3cd) e está incluída no Anexo I da CITES e na Lista das Espécies da Fauna Brasileira Ameaçada de Extinção. (IUCN, 2003; CITES, 2003) Esses chimpanzés são primatas tradicionais em jardins zoológicos de todo o mundo onde exercem forte atração sobre os visitantes. A adaptação de animais silvestres a novas condições ambientais e a integração de novos animais a um grupo já estabelecido são tarefas que exigem atenção especial por parte das equipes dos zoológicos com constantes avaliações. (KLEIMAN, 1996) 
Mamíferos sociais, como os chimpanzés, exigem atenção especial da parte dos jardins zoológicos, principalmente no que diz respeito à adequação dos recintos, à relação com o público e à reprodução. (GARCIA et al., 2001; LACERDA et al., 2001, YNTERIAN, 2004) A solução de conflitos entre grupos já estabelecidos em cativeiro é tarefa a ser tratada com base no conhecimento do comportamento dos animais e de intervenções criativas. (BOEHM, 1996)

O protocolo que apresentamos a seguir, em anexo, foi desenvolvido durante o ano de 1998 como parte dos preparativos para o recebimento de novos chimpanzés vindos do Jardim Zoológico de Lisboa para o JZB. Três casais de chimpanzés tiveram seu comportamento social estudado com o objetivo de acompanharmos a adaptação entre os novos animais e os que já faziam parte da coleção. Inicialmente, o casal de chimpanzés adultos residentes no JZB foi observado como preparativo para a chegada de dois outros casais. O casal residente era composto por dois adultos, e, dos novos casais, um era formado por adultos, e outro, por infantis. Posteriormente, à medida que os animais eram colocados em contato, os três casais foram observados para determinarmos o grau de adaptação dos novos animais ao JZB e dos indivíduos entre si.

\section{Material e métodos}

Dois casais de Pteronura brasiliensis e seus filhotes foram observados e tiveram seu comportamento descrito entre abril de 1995 e dezembro de 1998 . Os animais ocupavam um recinto de $1270 \mathrm{~m}^{2}$ dividido ao meio por uma cerca de metal. Na parte mais externa do recinto, há um espelho d'água com $210 \mathrm{~m}^{2} \mathrm{e}$ profundidade variando entre 45 a $105 \mathrm{~cm}$, que também é dividido ao meio pela cerca de metal. Durante o período de elaboração deste protocolo, os dois casais reproduziram-se e nasceram vinte e dois filhotes de seis ninhadas. (LOUZADA-SILVA \& SARTORI, 1998)

Um casal de adultos de Pan troglodytes que ocupava um recinto de $1.164 \mathrm{~m}^{2}$, com quatro cambiamentos, fosso e giral de madeira, foi reunido a outro casal também de adultos. Outros dois animais importados, um macho e uma fêmea, eram infantis, ficaram em outro recinto e foram observados separadamente. O repertório comportamental de chimpanzés no JZB foi elaborado tomando-se como referência o trabalho realizado com as ariranhas. Sua primeira versão utilizou apenas os animais já residentes no JZB que foram observados durante quinze dias.

Para as duas espécies, foram consideradas três grandes categorias de comportamento: 
a) comportamento individual;

b) interação entre indivíduos;

c) vocalização.

Para as ariranhas, a atividade "catação" foi incluída como comportamento individual e entre indivíduos, separando-se a autocatação da catação de outro indivíduo. Optou-se por incluir "oferecer peixe" como comportamento individual. No item vocalização, nossas observações levaram-nos a confirmar o que já havia sido descrito no trabalho de SALVO SOUZA \& BEST (1982). O repertório foi utilizado para observação diária da atividade das ariranhas em que se incluiu o nascimento e a criação de seis ninhadas. As observações estenderam-se por até 12 horas com início às 6:00 horas e término às 18:00 horas.

Para as duas espécies, utilizamos o método de varredura (scan sampling) com intervalos de cinco minutos entre cada evento, quando era anotado para cada indivíduo o primeiro comportamento que durasse mais de três segundo e sua distância ao vizinho mais próximo. (ALTMANN, 1974; MARTIN \& BATESON, 1992) Estes dados foram reunidos por períodos de uma hora, num total de doze eventos por hora, por exemplo, de 15:00h a 15:55h. Foram, ainda, considerados os locais em que cada animal se encontrava e, quando pertinente, suas atitudes em relação ao público visitante e aos funcionários do zoológico. A planilha desenvolvida para ariranhas pode facilmente ser adaptada para a compilação de dados de chimpanzés.

\section{Referências}

ALTMANN, J. “Observation study of behaviour: sampling methods”. In: Behaviour 49: 227-267. 1974

BOEHM, C. "Pacifying Intervention at Arnhem Zoo and Gombe". In Chimpanzee Cultures, WRANGHAM, R.C.et al (ed.), pp. 211-226. Harvard University Press. 1996.

BRASIL, Ministério do Meio Ambiente. Instrução Normativa n 3, de 27 de maio de 2003. Lista das Espécies da Fauna Brasileira Ameaçada de Extinção. 2003.

CABRERA, A. “Catálogo de los Mamíferos de America de Sur”. In: Revista del Museo Argentino de Ciências naturales Bernardino Rivadavia, tomo IV, $\mathrm{n}^{\circ}$ 1, Buenos Aires. 732 pp. 1957.

CARTER, S. K.; Rosas, F.C.W. "Biology and conservation of the giant otter Pteronura brasiliensis”. In: Mammal Rev.; 27(1):1-26. 1997.

CITES. Appendices I, II and III - valid from 16 October 2003. http://www.cites.org/eng/ append/appendices.pdf. 2003.

DUPLAIX, N. "Observations on the ecology and behaviour of the giant otter Pteronura brasiliensis in Suriname”. In: Rev. Ecol. (Terre et Vie) 34: 495-619. 1980. 
EMMONS, L.H. \& FEER, F. Neotropical Rainforest Mammals: a field guide. 2. ed. Chicago: The University of Chicago Press, 1997. 307 p.

ESTES, R.D. The Behavior Guide to African Mammals. The University of California Press, $1991.611 \mathrm{p}$.

FONSECA, G.A.B. et al. (ed.). Livro Vermelho das Espécies Ameaçadas de Extinção. Belo Horizonte: Fundação Biodiversitas, 1984. 459 p.

GARCIA, A.R.D.; PORTELLA A.S. \& JUÁREZ, K.M. "Enriquecimento ambiental com chimpanzés (Pan troglodytes) no Zoológico de Brasília”. In: UNIVERSITAS BIOCIÊECIAS, 2(1) 15-22. 2001.

IBAMA. Mamíferos Aquáticos do Brasil: Plano de Ação-Versão II. Brasília, DF. 96 p. 2001.

IUCN. 2003 IUCN Red List of Threatened Species. http://www.redlist.org/. 2003.

KLEIMAN, D.G. et al. Wild Mammals in Captivity Principles and Techniques. The University of Chicago Press, 1996. 637 p.

LACERDA. A.C. R.; GRANDO, R.S.C. \& BIZERRIL, M.X.A. "Efeitos da visitação pública e da estrutura de recintos sobre o comportamento do lobo-guará no Zoológico de Brasília". In: UNIVERSITAS-BIOCIÊECIAS, 2(1) 7-14. 2001.

LOUZADA-SILVA, D. \& SARTORI, A.A.S. "Reprodução e desenvolvimento de Ariranha Pteronura brasiliensis no Jardim Zoológico de Brasília”. In: Resumos da 8 a Reunião de Especialistas em Mamíferos Aquáticos da América do Sul \& $2^{\circ}$ Congresso da Sociedade Latinoamericana de Especialistas em Mamíferos Aquáticos-SOLAMAC, Olinda, PE, p. 117. 1998.

MARTIN, P. \& P.BATESON. Mesuring behaviour - An Introduction Guide. 2. ed. Cambridge: University Press, 1992. 222 p.

SALVO SOUZA, R.H.S. \& BEST, R.C. "Contribuição sobre o comportamento de ariranha (Pteronura brasiliensis Gmelin, 1788) em cativeiro”. In: Contribuição $n^{\circ} 34$ da Divisão de Mamíferos Aquáticos, INPA, Manaus 33 pp. 1982.

THORNBACK, J. \& JENKINS, M. (ed.). The IUCN Mammal Red Data Book: Part 1. International Union for Conservation of Nature and Natural Resources (IUCN), Gland. 1982.

WHITEN, A. \& BOESCH, C. "The Cultures of Chimpanzees". In: Scientific American, 284(1): 48-55. 2001.

YNTERIAN, P.A. (Editor) Nossos Irmãos Esquecidos. São Paulo: Terra Brasilis, 2004. 348.

AGRADECIMENTOS: Foram muitas as contribuições a este trabalho em suas diversas etapas, tanto de colegas do Jardim Zoológico de Brasília como de colegas e alunos do UniCEUB e a todos sou agradecido. Agradeço, particularmente, a Marisa Vieira de Carvalho e Jaqueline Moraes Farias do JZB; aos doutores Don Lindburg e Ron Swaisgood e a Helena Fitch-Snyder do Zoológico de San Diego; a Cláudio Henrique Cerri e Silva, Paulo Paniago Gomes Pereira, Rafael Cassilha Andrigueto, Sabrina Cândido Dematte, Bruna Borges Castro, Roberta Gomes Carvalho e Cibele Barbosa Rodrigues, do UniCEUB. 


\title{
Protocolo para a observação de ariranha (Pteronura brasiliensis) em cativeiro: repertório comportamental contextualizado
}

\author{
Daniel Louzada-Silva ${ }^{1}$ \\ Adriana de Almeida Santos Sartori ${ }^{1}$ \\ Aline Ramos Marques ${ }^{2}$ \\ Márcia Aparecida Godoy ${ }^{3}$
}

Anotam-se, a cada cinco minutos, todos os comportamentos observados por, pelo menos, três segundos consecutivos identificando o animal, a atividade, o local no recinto e o vizinho mais próximo. Qualquer comportamento relevante observado fora do período de amostragem deve ser também considerado. A distância ao vizinho mais próximo deve ser tomada de acordo com faixas com os animais em contato físico, separados por distância de até um metro, até dois metros, até três metros, e assim por diante.

\footnotetext{
${ }^{1}$ Faculdade de Ciências da Saúde - UniCEUB.

${ }^{2}$ Faculdade de Medicina Veterinária, UnB.

${ }^{3}$ Bolsista do Programa RHAE/CNPq.
} 
Protocolos comportamentais

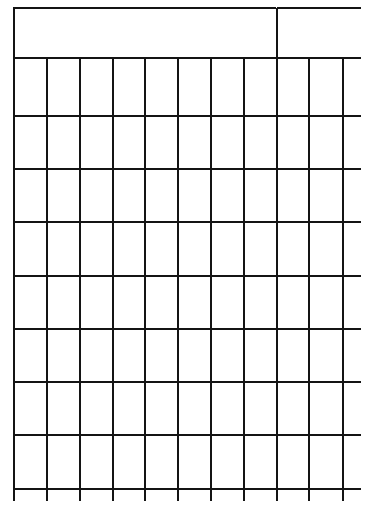




\section{COMPORTAMENTOS INDIVIDUAIS:}

\subsection{LOCOMOÇÃO:}

CÓDIGO ATIVIDADE

AN

Andar

GA

Galopar

$\mathrm{CO}$

Correr

ND Nadar

PA

Parado

\section{DEFINIÇÃo}

Deslocamento terrestre em que as patas anteriores e posteriores alternam-se ao tocar no chão, a cauda toca o chão e a cabeça balança para cima e para baixo. É um movimento desajeitado devido às adaptações dos animais para a natação.Anotar sempre que o comportamento durar mais de três segundos.

Deslocamento terrestre mais rápido que AN. As patas anteriores e posteriores aproximam-se mais umas das outras, o que provoca um maior arqueamento dorsal. A cauda encosta no chão quando o animal estende as patas anteriores para a frente. Anotar sempre que o comportamento durar mais de três segundos.

É o mais rápido dos deslocamentos em terra. $\mathrm{O}$ animal pode tirar todas as patas do chão simultaneamente. A cauda pode ficar ereta ou tocar no chão. Anotar sempre que o comportamento durar mais de três segundos.

Deslocamento aquático em que a cauda é movimentada lateralmente e as patas impulsionam o animal. Deve se considerar sempre que o comportamento durar mais de três segundos e anotar: Submerso (ND/SB) Sempre que a cabeça estiver totalmente abaixo do nível d'água. Quando o observador notar que a cabeça sai da água apenas para a respiração e a vigiância, caça, pesca, etc., continuam sendo feitas com o animal submerso, deve considerar todo o período como de ND/SB. Na superfície (ND/SP) O animal nada com as narinas e os olhos fora d'água. Girando em movimento rotatórios $(\mathrm{ND} / \mathrm{G}) \mathrm{O}$ animal nada girando o corpo em movimentos rotatórios dentro d'água deslocando-se para frente ou em círculos.

Quando o animal interrompe um movimento de locomoção, por exemplo, para observar algo dentro ou fora do recinto. Pode ocorrer em terra ou na água, com o animal apoiado em duas ou quatro patas. Anotar forma e local do animal parado sempre que o comportamento durar mais de três segundos.

\subsection{REPOUSO:}

DT Deitado

Quando o animal apóia o corpo no chão sem utilizar as patas para sustentação. É um comportamento que ocorre individualmente ou em grupo e está associado a repouso, brincadeiras, amamentação, banhos de sol e de terra.

Estado de repouso com o animal deitado e de olhos fechados podendo ser individual ou em grupo. $\mathrm{O}$ observador deve estar atento para não anotar DR em todas as ocasiões DR Dormir em que o animal estiver deitado de olhos fechados. É comum os animais permanecerem deitados por longos períodos sem realmente dormir e cabe ao observador desenvolver sua capacidade de distinguir entre estas situações.

ST Sentado

Estado de repouso em que o animal apoia a parte anterior do corpo nas patas enquanto a posterior permanece relaxada e em contato com o chão. 


\subsection{ATIVIDADES RELACIONADAS À HIGIENE E MARCAÇÃO:}

\begin{tabular}{|c|c|c|}
\hline $\mathrm{U}$ & Urinar & $\begin{array}{l}\text { Comportamento ocorre sempre em terra. Os adultos tendem a utilizar um local } \\
\text { específico, a latrina ou banheiro (BNH). SALVO SOUZA \& BEST ressaltam que o } \\
\text { animal aproxima-se do banheiro cheirando o chão e que se viram de costas para ele } \\
\text { antes de começar a urinar. O animal apóia as quatro patas no chão e a cauda é } \\
\text { flexionada para cima, podendo a ariranha dar alguns passos para frente enquanto urina. }\end{array}$ \\
\hline $\mathrm{DF} / \mathrm{U}$ & $\begin{array}{c}\text { Defecar e } \\
\text { urinar }\end{array}$ & $\begin{array}{l}\text { O animal urina e defeca simultaneamente. Comportamento ocorre sempre em terra. Os } \\
\text { adultos tendem a utilizar um local específico, a latrina ou banheiro (BNH). O animal } \\
\text { apóia as quatro patas no chão e a cauda é flexionada para cima, podendo a ariranha } \\
\text { dar alguns passos para frente durante esta atividade. SALVO SOUZA \& BEST não } \\
\text { descreveram U separadamente, mas não é sempre que o animal urina que ele também } \\
\text { defeca; a forma de aproximação do BNH é a mesma que em U. }\end{array}$ \\
\hline $\mathrm{DÇ}$ & Dançar & $\begin{array}{l}\text { O animal arrasta o ventre no chão com movimentos circulares das quatro patas para } \\
\text { espalhar os excrementos e esfregá-los no corpo. Comportamento observado apenas } \\
\text { em adultos quando saem das tocas ou da água. Pode começar com U e/ou DF/U e } \\
\text { prosseguir por vários minutos após o término de U e/ou DF/U .Anotar sempre que } \\
\text { ocorrer. }\end{array}$ \\
\hline Ctp & $\begin{array}{l}\text { Catação ou } \\
\text { "grooming" }\end{array}$ & $\begin{array}{l}\text { Comportamento realizado com o animal mordendo seu próprio corpo para retirar } \\
\text { ectoparasitas ou outros elementos que o incomodem. }\end{array}$ \\
\hline \multicolumn{3}{|c|}{ 1.4. MOVIMENTAÇÃO DE TERRA E CONSTRUÇÃO DE TOCAS: } \\
\hline $\mathrm{CV}$ & Cavar & $\begin{array}{l}\mathrm{O} \text { animal utiliza as patas anteriores e/ou posteriores para movimentar a terra. Este } \\
\text { comportamento está relacionado à construção de tocas, brincadeiras ou exploração do } \\
\text { ambiente. }\end{array}$ \\
\hline RL & Rolar na terra & $\begin{array}{l}\text { O animal gira o corpo sobre o chão e utiliza as patas e a cauda para jogar terra sobre } \\
\text { si. O animal gira o corpo } 360^{\circ} \text {, mas permanece em decúbito dorsal a maior parte da } \\
\text { atividade. }\end{array}$ \\
\hline
\end{tabular}




\subsection{ATIVIDADES RELACIONADAS À ALIMENTAÇÃO:}

$\mathrm{O}$ animal nada perseguindo um peixe ou cardume e captura a presa com a boca e/ou as patas anteriores. Comportamento em geral seguido de CM, mas pode estar

PS Pescar também associado a brincadeiras. No último caso é comum que o peixe seja deixado sobre a grama e que a ariranha se interesse por outro peixe. Às vezes a ariranha pega e solta o peixe seguidamente e pode arremessá-lo para cima e para os lados indo depois pegá-lo.

O animal nada ou corre perseguindo uma ave (garças e socós) e captura a presa com a boca e as patas anteriores. Em geral, a ave é capturada pelas patas. A ariranha CÇ Caçar arrasta a ave mordendo seu pescoço até dentro d'água e a morte é uma combinação de afogamento e ferimentos. Quando o animal é comido pela ariranha esta se interessa principalmente pelo ventre e pescoço.

O principal item alimentar no JZB é peixe, havendo exceção apenas para a eventualidade de as ariranhas comerem uma ave. Os animais podem comer dentro d'água, em terra ou apoiados nas patas anteriores com o tórax e cabeça fora d'água enquanto o resto do corpo fica submerso. Muitas vezes, principalmente quando há filhotes, o peixe é levado para dentro da toca. As ariranhas adultas comem os peixes, CM Vomer vivos ou mortos, a partir da cabeça (exceção para mandi que os animais rejeitam a cabeça, comendo apenas o resto do corpo). Os adultos seguram a presa com as duas patas anteriores utilizam os pré-molares e molares para arrancar pedaços e mastigá-los, sempre de lado, alternado direita e esquerda da boca. Os infantis começam a experimentar peixe entre a $10^{\mathrm{a}}$ e $12^{\mathrm{a}}$ semanas de vida quando mascam o peixe, mas ainda são incapazes de arrancar pedaços. Até a $44^{a}$ semana os infantis ainda não arrancavam pedaços como os adultos. Anotar sempre que ocorrer.

BE Beber

Comportamento observado quando o animal está em terra e ingere água do fosso. O mesmo deve ocorrer com o animal dentro d'água, mas não nos foi possível discriminar esta ação. Ocorre freqüentemente após o animal comer.

$\mathrm{O}$ infantil suga os mamilos da mãe para obter leite. Pode vir associado à vocalização dos infantis e da fêmea adulta. Os filhotes mamam até pelo menos a $20^{\mathrm{a}}$ semana de

MM Mamar vida. O filhote utiliza as patas empurrando a mama, aparentemente para aumentar o fluxo de leite que sai pelo mamilo. Anotar sempre que ocorrer. Especificar o início e fim da atividade.

Um indivíduo adulto leva para outro peixe vivo, morto ou mesmo em pedaços. Este comportamento é observado entre adultos e indivíduos de qualquer faixa etária ou sexo. Pai e mãe levam peixe para dentro da toca ou para os filhotes fora desta nos

OF Oferecer peixe primeiros meses de vida. O pai leva frequientemente peixe para a mãe dentro da toca no primeiro mês de vida dos filhotes. Animais de recintos diferentes levam peixe para os vizinhos. Algumas vezes as ariranhas trazem peixes para os pesquisadores na borda do recinto. Anotar sempre que ocorrer.

\section{INTERAÇÃO ENTRE INDIVÍDUOS:}

\subsection{RECONHECIMENTO MÚTUO:}

Ct Catação

FF Focinho-focinho

FG Focinho-genitália

FC

Focinho-chão
Um animal mordisca outro, presumivelmente, para a retirada de ectoparasitas. Deve ser anotado com $\mathrm{Ct}$ seguida da sigla do animal que faz a catação e uma seta indicando o animal que a recebe. Exemplo: Se a fềmea 1 cata o macho 1, anotar CT F1 M1.

Animal aproxima seu focinho do focinho de outro, com ou sem contato físico e cheira o outro ostensivamente. Comportamento associado à identificação olfativa e pode estar associado a algum tipo de vocalização. Exemplo: Se o macho 1 cheira o focinho do infantil 2, deve-se anotar M1 FF I2. Anotar sempre que ocorrer.

Ver Comportamento Reprodutivo.

Animal adulto cheira o chão procurando indícios de presença de outro. Comportamento provavelmente relacionado à detecção do estado reprodutivo de fêmeas. Na natureza pode estar, também, associado à detecção de indivíduos estranhos ao grupo. Anotar o animal que cheira e onde se dá o comportamento. Isto pode permitir relacionarmos o comportamento a alguma alteração fisiológica dos animais. Exemplo: Se o macho 1 cheira a prancha do recinto 1 anotar M1 FC PR1. 


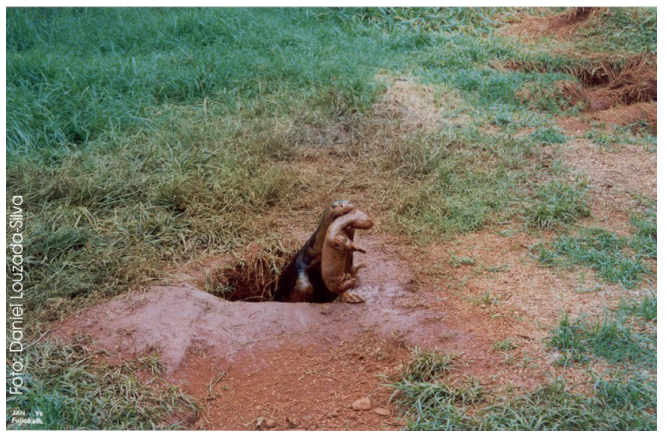

Figura 1a - Fêmea MA 1247 sai da toca carregando filhote de três semanas pela boca.

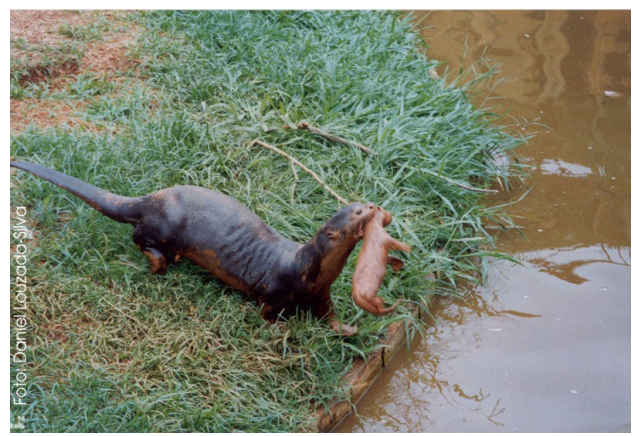

Figura 1b - Fêmea MA 1247 transporta filhote com a boca. Na sequência a fêmea entrou com o filhote na água e passou a lamber seu ânus (ver foto 2 a).

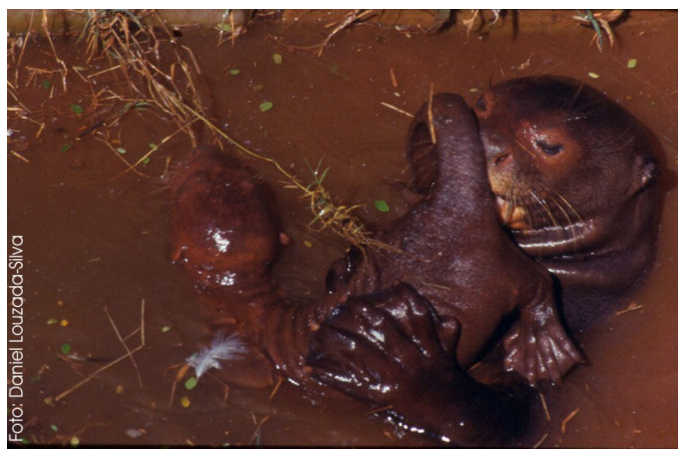

Figura 2a - Fêmea MA 1247 lambe ânus de filhote de três semanas dentro d'água. Filhote nascido em 15/04/1995. 


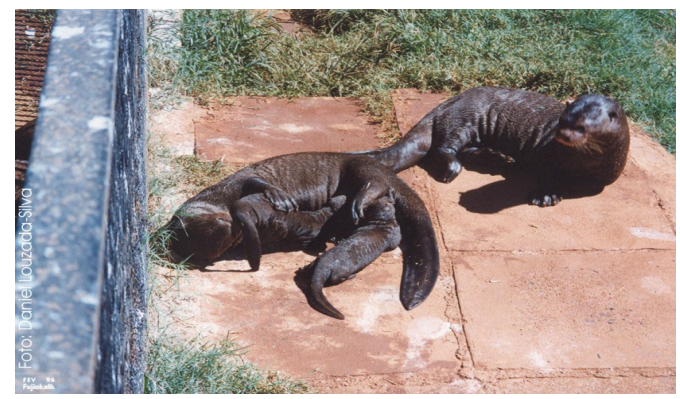

Figura 2b - Fêmea MA 1247 amamenta dois filhotes tendo ao lado o macho MA 1236 ao seu lado. Notar que enquanto amamenta, MA 1247 lambe o ânus de um dos filhotes. Filhotes com 10 semanas de idade, nascidos em 05/12/1995.

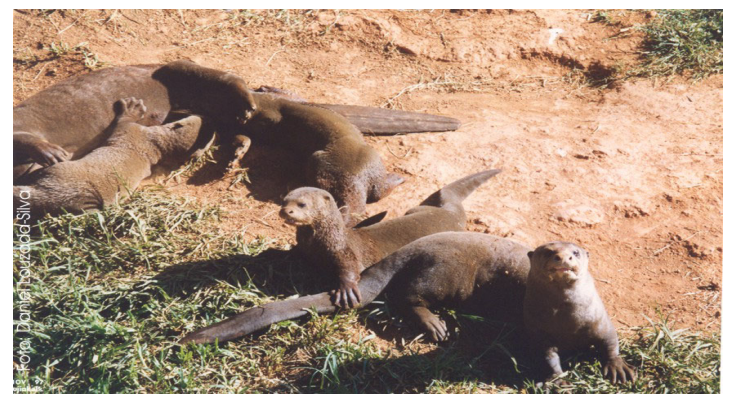

Figura 3 - Dois filhotes de 12 semanas de idade mamam. Um terceiro filhote aparece ao lado do pai, ambos em posição de alerta. Filhotes nascidos em 01/ 06/1997. Pai MA 1246 e mãe MA 1337.

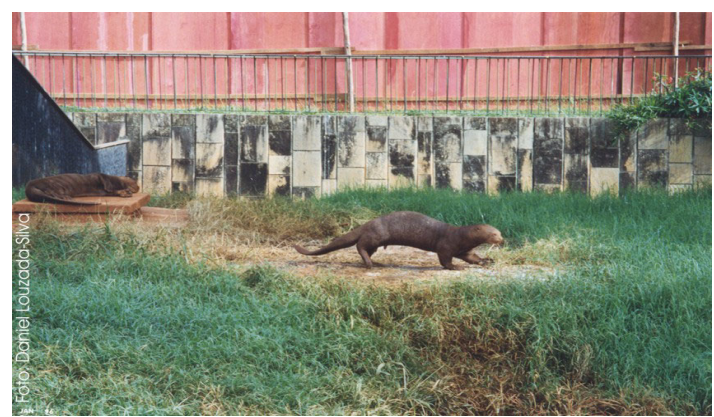

Figura 4 - Fêmea MA 1247 defeca e urina ao mesmo tempo em que dança sobre a latrina do recinto. $O$ macho MA 1236 aparece à esquerda da foto dormindo. 


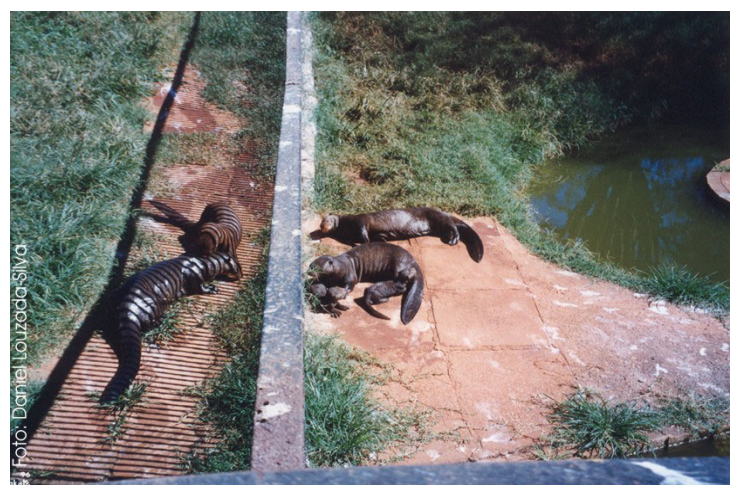

Figura 5 - À esquerda, o macho MA 1246 cata o pêlo da fêmea MA 1337 com a boca. À direita, a fêmea 1247 com dois filhotes observa e o macho MA 1236 dorme.

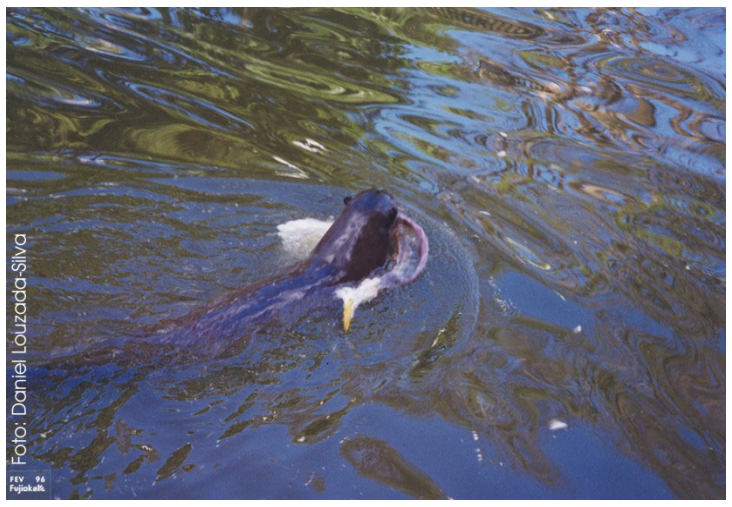

Figura 6 - Macho MA 1246 carrega uma garça-branca-grande (Ardea alba) que acabara de capturar. As aves são capturadas pelas pernas e logo a seguir atacadas no pescoço. Notar o pescoço já com a carne exposta. 


\title{
Protocolo para a observação de chimpanzés (Pan troglodytes) em cativeiro: repertório comportamental contextualizado
}

\author{
Daniel Louzada-Silva ${ }^{1}$ \\ Ana Rita Ferreira de Amorim ${ }^{1}$
}

Anotam-se, a cada cinco minutos, todos os comportamentos observados por, pelo menos, três segundos consecutivos identificando o animal, a atividade, o local no recinto e o vizinho mais próximo. Qualquer comportamento relevante observado fora do período de amostragem deve ser também considerado. A distância ao vizinho mais próximo deve ser tomada de acordo com faixas com os animais em contato físico, separados por distância de até um metro, até dois metros, até três metros, e assim por diante.

${ }^{1}$ Faculdade de Ciências da Saúde - UniCEUB 


\section{COMPORTAMENTOS INDIVIDUAIS}

\subsection{Locomoção}

\begin{tabular}{|c|c|c|}
\hline Código & Atividade & Definição \\
\hline $\mathrm{AD}$ & Andar & $\begin{array}{l}\text { O animal pode utilizar dois ou quatro membros. AD4: Membros } \\
\text { superiores e inferiores alternam-se ao tocar o chão. AD2: Só os } \\
\text { membros inferiores tocam o chão. }\end{array}$ \\
\hline GA & Galopar & $\begin{array}{l}\text { É um movimento de deslocamento, em que as patas e os braços se } \\
\text { alternam; é mais acelerado que andar. }\end{array}$ \\
\hline $\mathrm{CO}$ & Correr & $\begin{array}{l}\text { É um movimento acelerado com alternância de braços e pernas. O } \\
\text { animal chega a ficar totalmente sem tocar o chão. }\end{array}$ \\
\hline ND & Nadar & Comportamento não observado. \\
\hline PA & $\begin{array}{l}\text { Estar } \\
\text { parado }\end{array}$ & $\begin{array}{l}\text { É quando o animal não realiza movimento de deslocamento; pode } \\
\text { estar associado à observação ou repouso (cf. "Repouso"). O animal } \\
\text { pode estar parado com os quatro membros no chão (PA4) ou apenas } \\
\text { com os membros inferiores apoiados no chão (PA2). }\end{array}$ \\
\hline PE & Pendurado & $\begin{array}{l}\text { É o animal apoiado ou pendurado em tronco, escada, balanço ou } \\
\text { árvore, balançando para pular de um tronco para o outro ou apenas } \\
\text { para descansar. Filhotes comem também pendurados. }\end{array}$ \\
\hline PU & Pular & $\begin{array}{l}\text { O animal tira todos os membros do chão ao mesmo tempo. Pode } \\
\text { acontecer para chamar a atenção. Quando ficam nervosos, pulam e, } \\
\text { em seguida, batem em alguma coisa como a parede. Pode estar } \\
\text { associado ao arremesso de objetos. }\end{array}$ \\
\hline
\end{tabular}

\subsection{Repouso}

\begin{tabular}{|c|c|c|}
\hline DT & Deitado & $\begin{array}{l}\text { O corpo é estendido sobre o chão ou giral, de barriga para cima, } \\
\text { para baixo ou, ainda, de lado. Relaciona-se a repouso, catação (tanto } \\
\text { individual como em grupo), banho de sol, brincadeiras e cópula. }\end{array}$ \\
\hline DR & Dormir & $\begin{array}{l}\text { É o estado de repouso em que o animal fica deitado com os olhos } \\
\text { fechados, a respiração lenta e compassada. O animal pode } \\
\text { movimentar-se durante o sono procurando posição mais confortável. } \\
\text { É difícil precisar se o animal está realmente dormindo ou só deitado. }\end{array}$ \\
\hline ST & Sentado & $\begin{array}{l}\text { É a forma de repouso em que tórax e cabeça não encostam o solo } \\
\text { enquanto nádegas e pés tocam o chão. Está associado a repouso, } \\
\text { interação social, catação, alimentação e observação. }\end{array}$ \\
\hline $\mathrm{EN}$ & Encostado & $\begin{array}{l}\text { O animal fica sentado, mas apóia o corpo em parede, tronco, porta. } \\
\text { É associado a repouso, alimentação e observação. }\end{array}$ \\
\hline
\end{tabular}




\begin{tabular}{|c|c|c|}
\hline $\mathbf{U}$ & Urinar & $\begin{array}{l}\text { Geralmente, os adultos, ao contrário dos filhotes, urinam fora da vista } \\
\text { do observador. Os filhotes urinam pendurados em grades, árvores, } \\
\text { ou sentados em troncos e no chão. Um macho adulto, Júnior (JR), } \\
\text { foi observado urinando no giral. Uma fêmea adulta, Tota (TT), foi } \\
\text { observada urinando na mão e, depois, bebendo a urina. }\end{array}$ \\
\hline DF & Defecar & $\begin{array}{l}\text { Os adultos, geralmente, defecam no fosso, nas calhas, no } \\
\text { cambiamento ou na grama, em geral, fora da vista do observador. Os } \\
\text { filhotes defecam em todo o recinto e às vistas do observador. Anota- } \\
\text { se sempre o local onde ocorre ou onde foram observadas fezes } \\
\text { mesmo sem saber que animal defecou. }\end{array}$ \\
\hline CA & Coprofagia & $\begin{array}{l}\text { O animal leva fezes com as mãos à boca e come-as. Anota-se sempre } \\
\text { que ocorre indicando indivíduo e local. }\end{array}$ \\
\hline $\mathrm{Ct}$ & $\begin{array}{l}\text { Catação ou } \\
\text { "grooming" }\end{array}$ & $\begin{array}{l}\text { O comportamento é realizado com a boca e as mãos. O animal pode } \\
\text { catar seu próprio pêlo, anotando-se a sigla do indivíduo e a ação. } \\
\text { Exemplo: Se Júnior faz autocatação, anotar JR CTp. Quando um } \\
\text { indivíduo cata outro, anotar a sigla do animal, o comportamento (Ct) } \\
\text { e uma seta indicando o animal que a recebe a catação. Exemplo: Se } \\
\text { o Júnior cata a Tota, deve-se anotar JR Ct (R) TT. }\end{array}$ \\
\hline $\mathrm{Ch}$ & Cheirar & $\begin{array}{l}\text { O comportamento é associado ao reconhecimento dos indivíduos ou } \\
\text { de algum estado fisiológico particular. Podem cheirar também algum } \\
\text { outro animal ou alguma área ou algo específico, como o chão ou as } \\
\text { fezes. Geralmente, os machos cheiram a genitália das fêmeas, e as } \\
\text { fêmeas, a genitalia de outra fêmea. Anota-se a sigla de quem cheira, } \\
\text { seguida do comportamento e a parte do corpo ou a coisa que é } \\
\text { cheirada, seguida da sigla do animal alvo ou local.Exemplo } 1: \text { Se o } \\
\text { Charles (CH) cheira genitalia de Maria (MA), deve-se anotar CH } \\
\text { Chgn MA.Exemplo } 2 \text { : Se Tota cheira comida, anota-se TT Ch } \\
\text { comida. }\end{array}$ \\
\hline
\end{tabular}
$\begin{array}{ll}\text { CR Coçar } & \text { Passa-se a măo no corpo com movimentos rápidos. A grama também } \\ \text { pode ser usada no lugar das mãos. }\end{array}$

\subsection{Movimentação de terra}

\begin{tabular}{ll}
\hline & O animal utiliza os membros anteriores para movimentar a terra. Este \\
CV Cavar & comportamento está relacionado a brincadeiras ou exploração.
\end{tabular}

\subsection{Atividades relacionadas à alimentação}

\begin{tabular}{|c|c|c|}
\hline $\mathrm{CM}$ & Comer & $\begin{array}{l}\text { Eles comem verdura, legumes (principalmente as raízes), frutas e } \\
\text { sementes, alem de insetos e, de vez em quando, comem carne. Levam } \\
\text { a comida à boca com as mãos ou, apenas, abaixam-se e pegam o } \\
\text { alimento com a boca. Os adultos só se alimentam no final da tarde, } \\
\text { mas, às vezes, comem o que o recinto pode-lhe proporcionar de } \\
\text { alimento, como grama, formiga, cupim, folhas. JR foi observado } \\
\text { comendo um passarinho. Anota-se o animal seguido de CM e do } \\
\text { alimento que o bicho está comendo. Exemplo: Se Leila (LE) come } \\
\text { beterraba, anota-se LE CM beterraba. }\end{array}$ \\
\hline FR & $\begin{array}{l}\text { Forrageam- } \\
\text { ento }\end{array}$ & $\begin{array}{l}\text { É quando catam algo na grama, tronco, concreto ou cupinzeiro e } \\
\text { levam á boca. Acontece geralmente na grama. Anota-se: FRg na } \\
\text { grama, FRtr no tronco, FRcc no concreto e FRcu no cupinzeiro. }\end{array}$ \\
\hline BE & Beber & $\begin{array}{l}\text { Eles abaixam-se levando a boca em direção à água para bebê-la ou } \\
\text { usam as mãos. }\end{array}$ \\
\hline PDA & Pedir algo & $\begin{array}{l}\text { Pedir algo para uma pessoa ou para outro chimpanzé esticando um } \\
\text { dos braços com a palma da măo virada para cima. Geralmente, } \\
\text { pedem comida, também pedem brinquedos ou, até mesmo, carinho. }\end{array}$ \\
\hline
\end{tabular}


2. INTERAÇÃO ENTRE OS INDIVÍDUOS

\subsection{Reconhecime nto mútuo}

\begin{tabular}{|c|c|c|}
\hline Ch & Cheirar & O mesmo descrito anteriormente. \\
\hline \multicolumn{3}{|r|}{2.2 Comportame nto reprodutivo } \\
\hline Chgn & $\begin{array}{l}\text { Cheirar } \\
\text { genitália }\end{array}$ & $\begin{array}{l}\text { Um animal aproxima sua narina na genitália de outro animal, podendo } \\
\text { ou não ter contato físico. Este comportamento pode estar associado } \\
\text { à atividade de cópula ou reconhecimento. Exemplo: Se Charles cheira } \\
\text { genitália de Maria, anota-se CH Chgn (BMA }\end{array}$ \\
\hline$C_{p}$ & Cópula & $\begin{array}{l}\text { Ocorre quando a fêmea está no cio. O macho fica em cima da fêmea } \\
\text { e penetra seu pênis na vagina. A fêmea pode estar deitada de barriga } \\
\text { para cima ou com os quatro membros no chão. Se Junior copula com } \\
\text { Maria, anota-se JR Cp MA. }\end{array}$ \\
\hline Er & Ereção & $\begin{array}{l}\text { É quando o pênis fica ereto e não está, necessariamente, associado à } \\
\text { cópula. Anota-se sempre que acontece. }\end{array}$ \\
\hline Cio & Cio & $\begin{array}{l}\text { O estado fisiológico das fêmeas é observado pelo inchaço na região } \\
\text { ano-genital. }\end{array}$ \\
\hline MT & $\begin{array}{l}\text { Masturbaç- } \\
\text { ão }\end{array}$ & $\begin{array}{l}\text { O comportamento é observado em machos e fêmeas. O animal } \\
\text { estimula a região genital com as mãos. Foi observado com o JR e } \\
\text { com MA, que, deitada com a barriga para cima, pega um punhado } \\
\text { de grama e excita a genitália. Anota-se sempre que acontece. }\end{array}$ \\
\hline $\mathrm{Cg}$ & $\begin{array}{l}\text { Contato } \\
\text { genital sem } \\
\text { ereção }\end{array}$ & $\begin{array}{l}\text { Dois animais encostam a genitália de um na do outro, mas não há } \\
\text { ereção. Foi observado entre Charles e Maria. Anota-se o nome de } \\
\text { um dos animais seguido de } \mathrm{Cg} \text {, um traço e o nome do outro animal. } \\
\text { Ex.: CH Cg B MA. Anota-se sempre que acontece. }\end{array}$ \\
\hline Ap & $\begin{array}{l}\text { Apresenta- } \\
\text { ção ou } \\
\text { provocação }\end{array}$ & $\begin{array}{l}\text { Chama-se estendendo a mão ou faz-se algum movimento ou posição } \\
\text { sinuosa para cópula, catação, brincar, ou só para chamar a atenção. } \\
\text { Anota-se sempre que acontece. }\end{array}$ \\
\hline
\end{tabular}

\subsection{B rincadeiras}

Brincam sozinhos, uns com os outros, com ou sem objetos. Qualquer objeto pode servir de brinquedo. Anota-se o indivíduo seguido de $\mathrm{Br}$ Br Brincar e o outro indivíduo e/ou objeto. Exemplo 1: Se Tota brinca com um galho, anota-se TT Br galho.Exemplo 2: Se Dunga brinca com Leila, anota-se DU Br LE.

\subsection{Vigilância} \begin{tabular}{ll}
\hline & É quando um animal protege outro de algo ou de outro animal \\
Pr Proteção & abraçando ou batendo no animal agressor. Exemplo: a Tota protege a \\
Maria de Charles. Anota-se TT Pr Ma de CH.
\end{tabular} Maria de Charles. Anota-se TT Pr Ma de CH.

Brg Briga E quando dois ou mais animais se agridem. Anota-se sempre que acontece.

\begin{tabular}{|c|c|c|}
\hline \multicolumn{3}{|r|}{ 3. VOCALIZAÇÃO } \\
\hline VCf & $\begin{array}{l}\text { Vocalização } \\
\text { fechada }\end{array}$ & $\begin{array}{l}\text { E quando fazem bico e soltam som grave; associa-se à tristeza ou a } \\
\text { chamamento de alguém. }\end{array}$ \\
\hline VCa & $\begin{array}{l}\text { Vocalização } \\
\text { aberta }\end{array}$ & $\begin{array}{l}\text { Abrem a boca e soltam som agudo. Parece com o nosso grito, é } \\
\text { associado com medo ou nervosismo }\end{array}$ \\
\hline \multicolumn{3}{|r|}{ 4. OUTROS COMPORTAMENTOS } \\
\hline $\mathrm{BO}$ & Bocejar & Com o sono, eles bocejam. \\
\hline $\mathbf{B P}$ & $\begin{array}{l}\text { Bater } \\
\text { palmas }\end{array}$ & $\begin{array}{l}\text { Batem palmas para chamar a atenção. Às vezes, pode estar } \\
\text { relacionado com nervosismo ou a brincadeiras. }\end{array}$ \\
\hline BT & Bater & $\begin{array}{l}\text { O animal bate em algum lugar ou } \mathrm{em} \text { um indivíduo. Anota-se sempre } \\
\text { que acontece. }\end{array}$ \\
\hline FE & $\begin{array}{l}\text { Uso de } \\
\text { ferramentas }\end{array}$ & $\begin{array}{l}\text { Usam ferramentas para pegar comida, ou outra coisa. Usam, também, } \\
\text { para brincar. São troncos, varetas, pedras. }\end{array}$ \\
\hline$A B$ & Abraço & $\begin{array}{l}\text { Quando ficam com medo, abraçam-se e VCf. Abraçam-se, também, } \\
\text { como forma de proteção e carinho. }\end{array}$ \\
\hline AR & Arrepio & $\begin{array}{l}\text { É observado com o eriçar (arrepio) dos pêlos. Geralmente, está } \\
\text { relacionado à irritação ou medo. }\end{array}$ \\
\hline As & Assustar & $\begin{array}{l}\text { É quando o animal se assusta com algum barulho ou movimento de } \\
\text { outro animal. }\end{array}$ \\
\hline GE & Gesto & $\begin{array}{l}\text { É quando o animal faz qualquer outro gesto diferente. Exemplo: fazer } \\
\text { careta, acariciar, contar os dedos, balançar o corpo, mandar beijo, } \\
\text { etc. }\end{array}$ \\
\hline
\end{tabular}

